
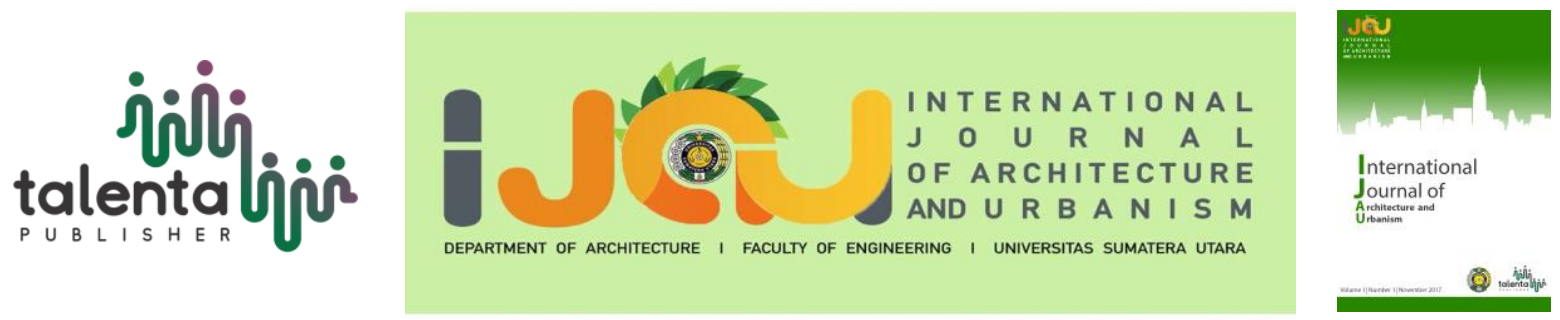

\title{
The Design Karo Cultural Centre with Neo- Vernacular Architecture Approach
}

\author{
Wahyuni Zahrah $^{1}$, Muhammad Yusuf Rahmadani ${ }^{{ }^{*}}$ \\ ${ }^{1}$ Architecture Department, Faculty of Engineering, Universitas Sumatera Utara, Medan, Indonesia
}

\begin{abstract}
Culture in North Sumatra is a very scant appreciation from the public. In particular, the community's enthusiastic Karo Ground against art objects tend to be low and continues to decline; it is also affected by the impact of the modernization of Western culture. It is required for a container or a place that is used to introduce, studying, preserving culture Karo, addressed to the community, domestic and foreign, the purpose is to make many parties better understand or know about the culture that exists in the land of Karo. Neo vernacular Karo was chosen as the theme of the design so as not to eliminate the side of culture Karo as well as local wisdom applied physical and nonphysical. The theme is used in the concept of building mass Si Walu Jabu into the project by taking the basic shapes in Karo, as well as custom homes, apply flexibility in floor plan traditional house Karo on every space in the cultural center. Design of area designated as Tahura with consideration of its strategic footprint and also as the gateway tour in the land of Karo. Expected with the existence of this cultural center, domestic and foreign, and especially the community can engage in its own agenda in the preservation, experience, recognition, and can enjoy Karo culture itself comfortably.
\end{abstract}

Keyword cultural, neo vernacular

\section{Introduction}

As we know, Indonesia is a country with a wide range of tribes and cultures. From Sabang to Merauke lies the Islands are inside are a variety of cultural and Tribal Nation Indonesia. Karo is a tribal tribe who inhabit the plateau of Karo. Batak Karo community itself resides in the area northwest of Lake Toba which covers an area of approximately 5,000 square kilometers of astronomically lies roughly between $3^{\circ}$ and $3^{\circ} 30^{\prime \prime}$ North latitude and $98^{\circ}$ and $98^{\circ} 30^{\prime \prime}$ East longitude.

Cultural heritage in the land of Karo can we see from the start the potential natural environment, customs, rites, sacred and secular, historical relics, traditional knowledge systems, conventional weapons, historical places, as well as art and culture all of which it is the capital and resources

*Corresponding author at: Departement of Architecture, faculty of Engineering, Universitas Sumatera Utara,

Jalan Perpustakaan, Building J07, Medan 20155, Indonesia

E-mail address: muhammady758@gmail.com 
to development efforts, increased utilization, and optimally to various interests, one of which is tourism

The utilization of cultural heritage as capital must be carried out optimally through the holding of tourism were kind, smart and independent, which generally aims to increase people's income or economic agenda in particular.

About culture, it is not only preserved but should be studied with the plunge of the practice to get the "typical experience" in each person who reviews it. Without culture, there will be no human diversity and lifestyle. Religion in North Sumatra is a very scant appreciation from the public. In particular, the community's enthusiastic Karo Ground against art objects tend to be low and continuing to decline also affected by the impact of the modernization of Western culture. Then there is the public perception that it is not essential which needs. A container or a place that is less good also gained contributes to this issue. This is evident in the number of visitors in museums on the ground such as Karo, the museum of Lingga (Phallus), the museum of JaminGinting (Tigapanah) and Karo heritage museum (Berastagi) very few numbers of visitors. Many assume that a community museum is a place that is boring. This is due to the building or container provided less attractive coupled with bad management, regarding the control of the exhibition, collection, hygiene, and others.

For it takes a container that can change public perception about matters related to culture, it is not essential, a place that is tedious and also the artists that got less appreciation can be given a chance to exist back in an adequate container that is a cultural center. The cultural center is a container or place intended to introduce, studying, preserving culture Karo, addressed to the community, domestic and foreign tourists to better understand or know about the culture. There is in the land of Karo.

\section{Literature Study}

The location of the Project is in Tahura, JL. JaminGinting, excl. Dolatrakyat Karo Regency, North Sumatra. Bordering the North (Deli Serdang), South (Tigapanah), Western (Berastagi), East (Barusjahe). Tahura as an area of design with consideration of a strategic site and also as the gateway tour in the land of Karo. Expected with the existence of this cultural center, domestic and foreign, and mainly the community has survived, could own Karo enjoy comfortably and to get better to know what kind of culture Karo itself.

Preview Theme, The themes raised at the Design Center of culture Karo is an "Architectural Vernacular Neo." Neo-Vernacular Architecture is familiar from the post-modern Architecture that was born as a response and critique of modernism that prioritizes the values of rationalism and functionalism influenced the development of technology industries. Neo-Vernacular Architecture is the architecture concept in principle considering the norms, normative role, the 
cosmological as well as local culture in public life as well as the harmony between the building, nature, and the environment [1].

Comparative Study, Buildings this Indonesia cultural center was completed in the wake of the year 2015, through the process of a competition held by the IAI and won by the KarimuddinTedjo and his team. Located in Dili, East Timor as a form of cultural cooperation between the two countries, which are the population of East Timor is still in touch with Indonesia (Figure 1).

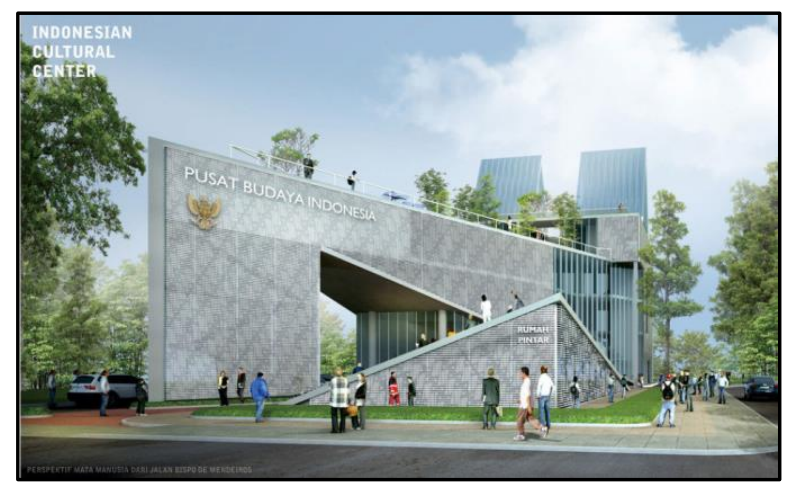

Figure 1. Indonesia culture center

Source: https://www.google.com/=pusat+kebudayaan+indonesia

The design of the building takes the form of a formal reflecting Indonesia 2015 with the abstract character of the ship on the entire structure; the describe Indonesia as a thalassocracy. While the facade adopted the visual pattern of Batik Indonesia. And this building consists of 4 floors and one basement.

Activity in this building is: (1) The presence of learning activities or construction in good with the learning spaces. (2) The existence of a cultural exhibition activities-a place for cultural performances or art. (3) Amphitheater, activity meetings were supported with an on-site Auditorium. (5) Reading in the library and Aliyev cultural center.

Cultural Center Aliyev, This building is the center of the Azerbaijan culture produced through a competitive process in WINS by Zaha Hadid. Construction with $57.500 \mathrm{~m} 2$ was completed on ten May 2012 in the city of Baku, Azerbaijan (Figure 2). 


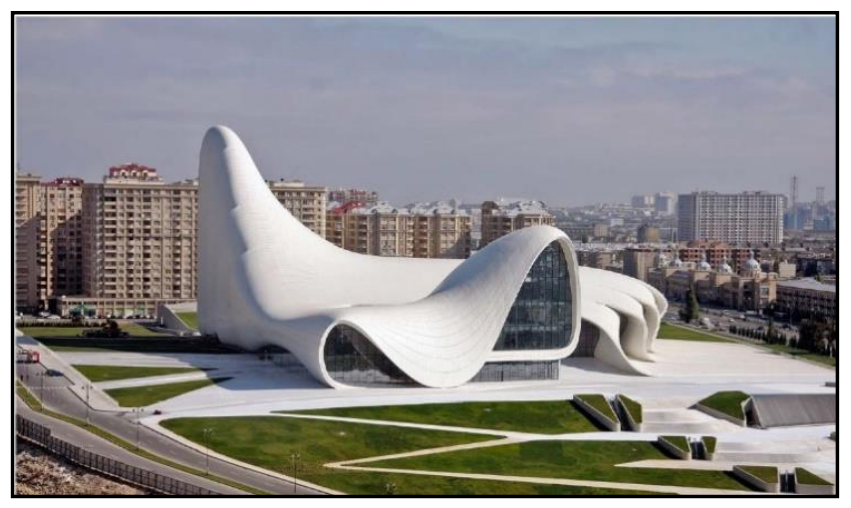

Figure 2. Perspective Aliyev

Source:https://www.google.com/=perspective+aliyev

The building has three main structures of Museum functions, conference room, library. Zaha Hadid approaches on Organic Architecture (adjust against nature). That is where the building is like a giant curve mutually connect; the pattern curve shaped as the field of aerodynamics to resist strong wind gusts in the city of Baku. This is also the solution design against the building.

The Philippine Pavilion represents the Progress Philippines and all its institutions. With the theme "progression towards harmonization of cultural diversity," this exhibition showed the Philippines in the context of the community and the aspirations, activities, and accomplishments of theirs (Figure 3).

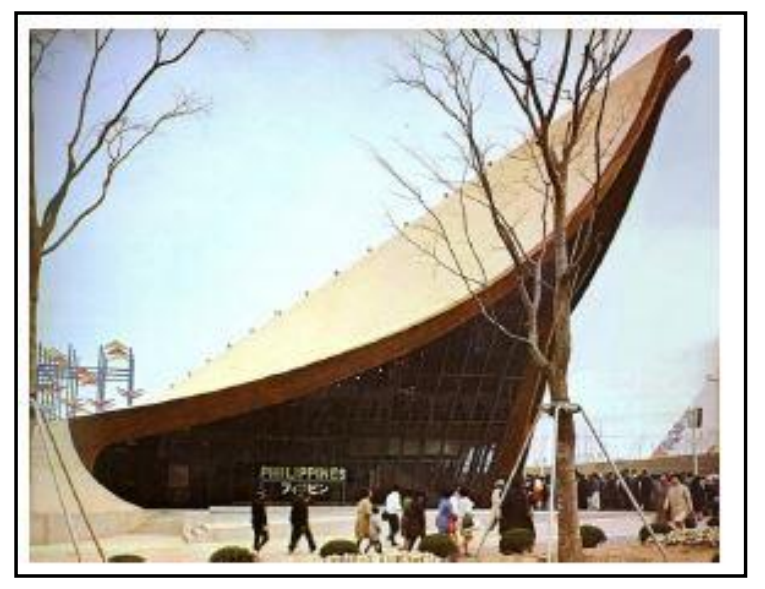

Figure 3. Exterior building Philippine Pavilion of Progress, of EXPO of EXPO 70.'

Source:https://www.google.com/= Philippine+Pavilion

Dramatic elections caused the roof from the ground to the sky as the Philippines is meant to look ahead. The message architecture is through the Philippines is a young and growing country, they have the determination to develop. Another vernacular side can be seen from its typical Philippine hardwood material, and other local materials are used entirely at the Pavilion. Exhibition in the pavilion is in the form of recording the history of the country of the Philippines. Soekarno-Hatta International Airport is the main airport serving Jakarta, Java, 
Indonesia. Located in the suburban city of Jakarta with a capacity of 9 million people. Designed by Paul Andreu of France. (Figure 4).

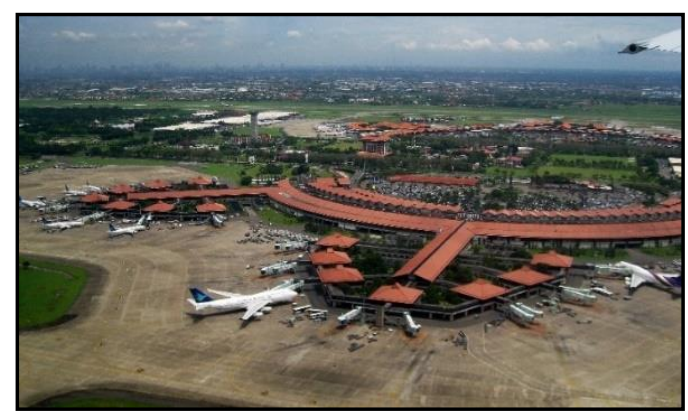

Figure 4. Soekarno Hatta perspective

Source:https://www.google.com/=Soekarno Hatta

Most of the units of the pillars and beams of Jogja (steel pipes) are exposed. Units in the terminal are connected with the very open lobby of tropical so that visitors feel the natural air and sunlight. The group uses the architecture lounge Joglo in large dimensions, but the shape and construction of the system not unlike the Sopo teachers and Usuk, Dudur, Takir and other construction elements of Java such as in the picture (Figure 5).

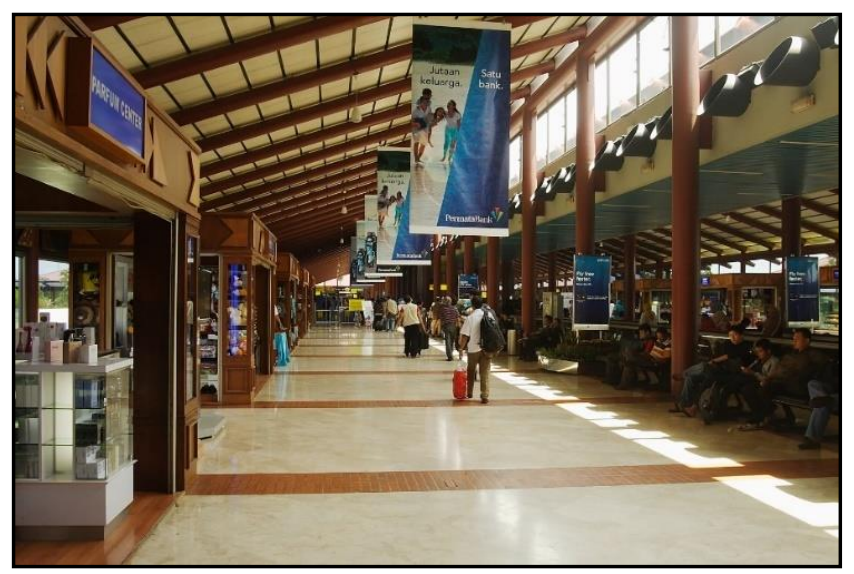

Figure 5. Interior Soekarno Hatta airport

Source:https://www.google.com/=interiorSoekarno Hatta

On the use of the image material, modern interior but has the look of a hardwood such as applied on the columns waiting gives the impression that modern yet natural. The use of advanced materials but has a look like wood is applied to the columns in the waiting room gave the idea of a modern yet natural. Soekarno-Hatta Airport is a building of Neo-Vernacular very clearly shows the original concept of vernacular as at the use of Joglo roof forms and roofsgable (folding) that is widely used in traditional structure Indonesia. 


\section{Methodology}

The method of data collection is done with the selection of primary data through a process of the comparative study of secondary data and field through the review of literature study \& appeal. The design approach used in the design of Culture Center Karo.

Field Studies, i.e., analyze physical conditions around the site, the potential, limits that existed at site b: environmental footprint and Approach, i.e., analysis concerning the status of the site and the best solution. User Approach, i.e., review of buildings to meet the needs of education and recreation facilities d. Study of literature related to the title and theme and the theories that support the idea of design and the analysis was done based on the results of the study the study literature related actors, activities and spaces, and environmental footprint in order to search for the principles, concepts, and characteristics suitable for the design of Culture Center project Karo.

\section{Result of Discussion}

For the application of the basic concept on building cultural centers Karo with through the natural neo theme approach, will be carried out by taking the idea of the traditional House of Karo in a way intangible and tangible.

Traditional House Karo (Si Walu Jabu), home of the Pumpkin Jabu is intended for the eight families (Jabu) who has a family connection to each other. The arrangement of space for each family is set by the position and function of each family (Figure 6).

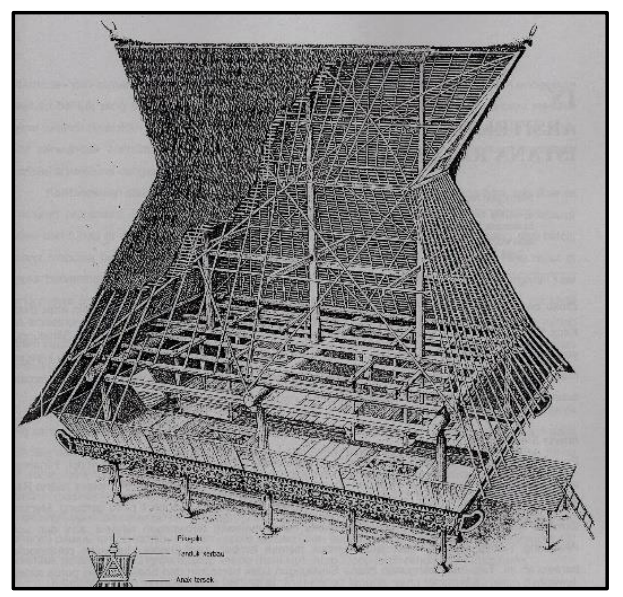

Figure 6. Traditional home Karo

Source:https://www.google.com/= Rumah Tradisional Karo

The flexibility of the use of space is a trait can potentially use a space for various properties and activities and maybe making the conversion arrangement of areas to suit your needs without changing the structure of the building [2]. 
A flexible Movement, with the made movement spaces which can be wherever comfortable or versatile (Figure 7).

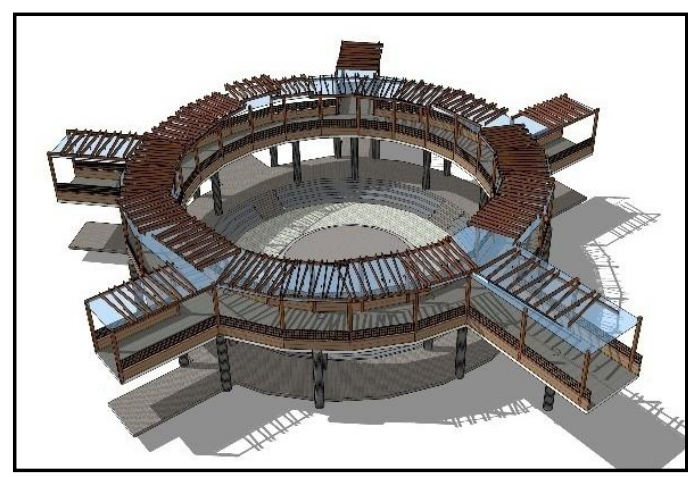

Figure 7. Sky bridge concept

Build The Base, The central mass of the building at the Centre of culture Karo took the form of a traditional house roofs Karo (Si Walu Jabu). Can be seen in (Figure 8) the silhouette from the roof through the Pumpkin becomes transform and then in Jabu some form.

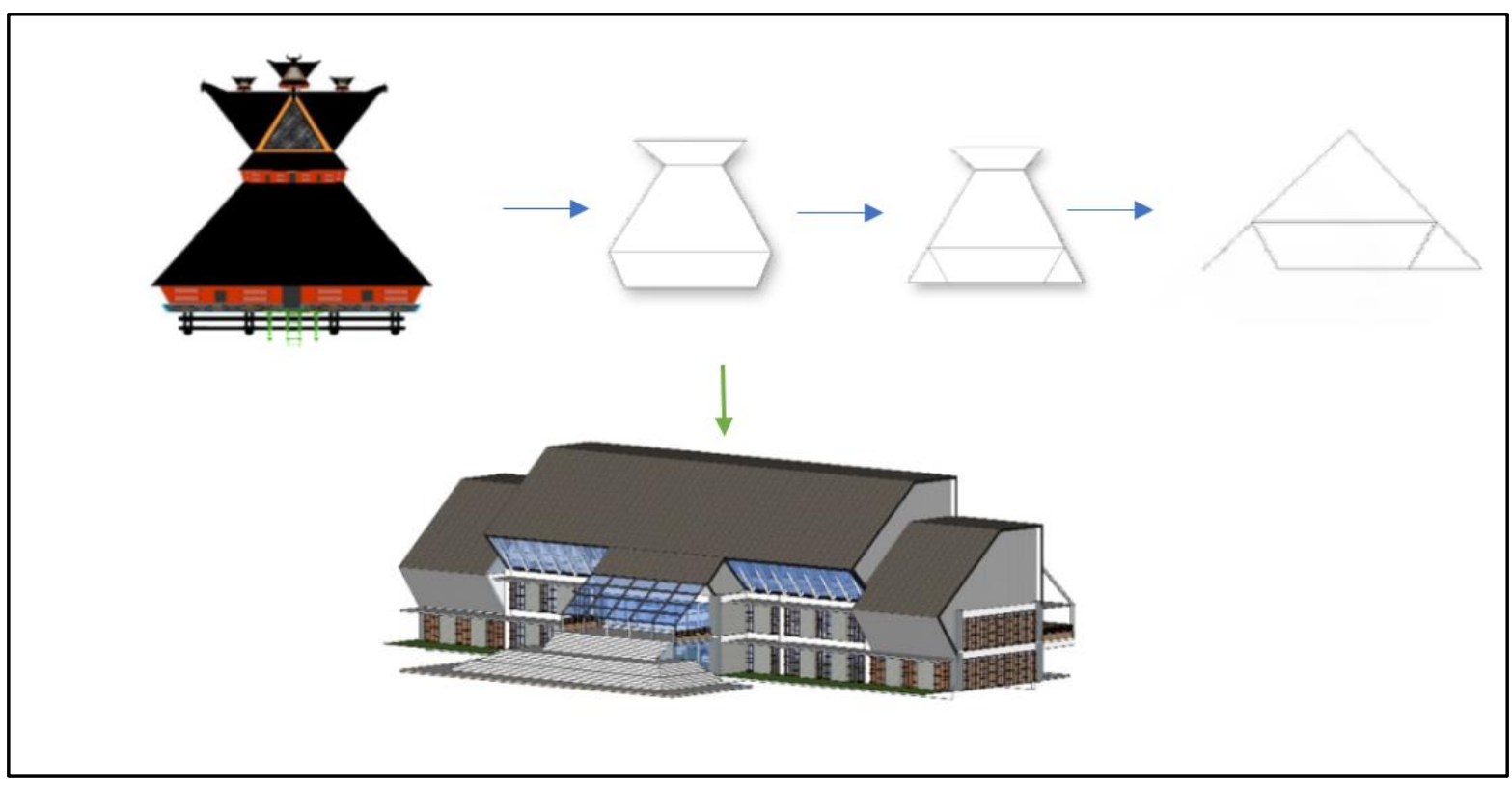

Figure 8. Building concept

You can see from the image above through some process of transformation of a traditional house roof until it becomes a mass. The building, which is a representation of the traditional structure Si Walu Jabu (Figure 8).

On building made to look more contemporary form of the bed base. On the front facade can be seen in (Figure 9). There is a vertical garden in glass-glass buildings. It was created as a solution design to minimize solar heat from the light on because dealing directly towards the East and the West. 




Figure 9. Facade

A picture of the four sides of the main building seems the result of processes of representation (Figure 10).

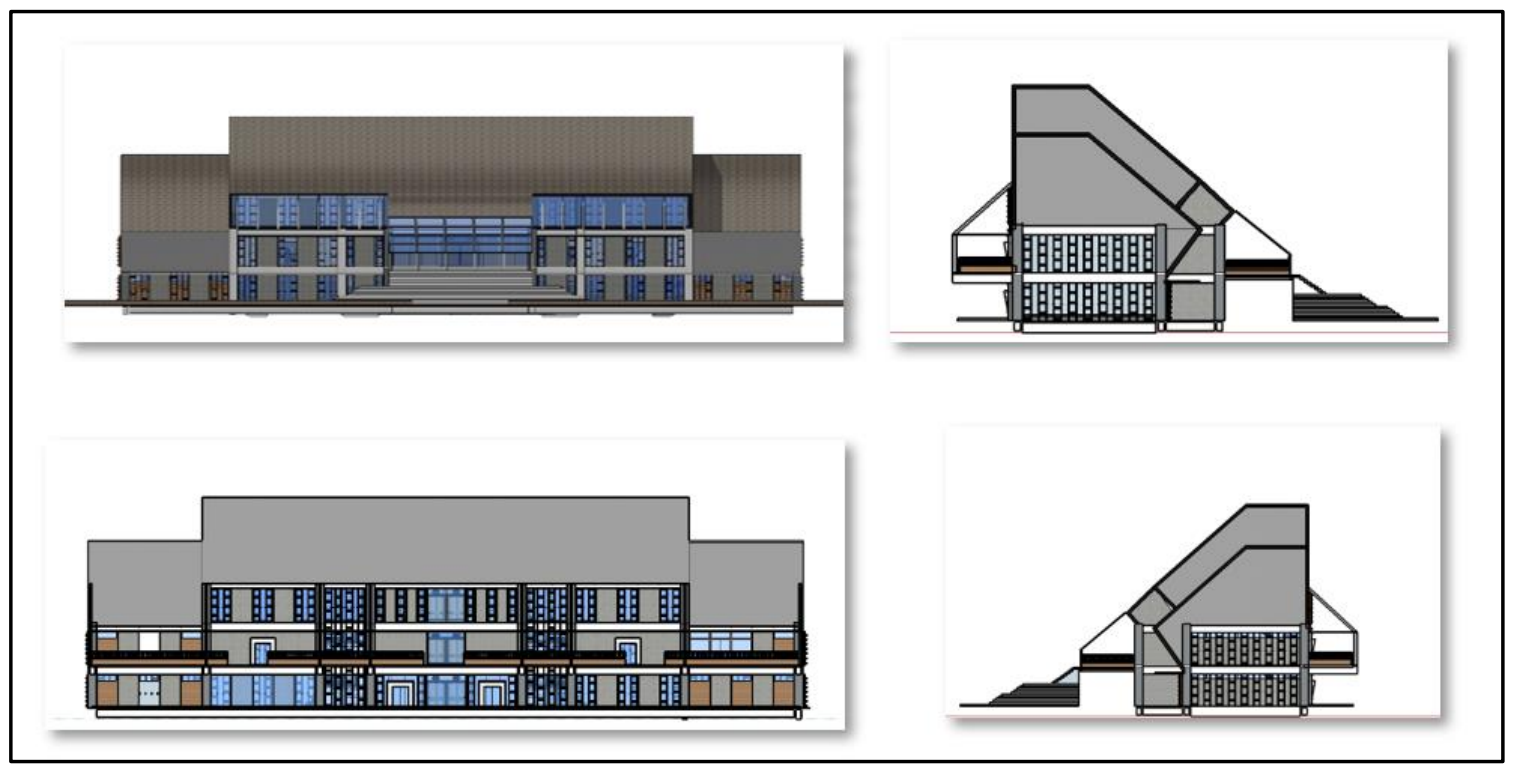

Figure 10. Main building

As for the structure of the workshop also to the concept of building a studio. The mass of the building comes from the silhouette of the traditional house Karo (Figure 11).

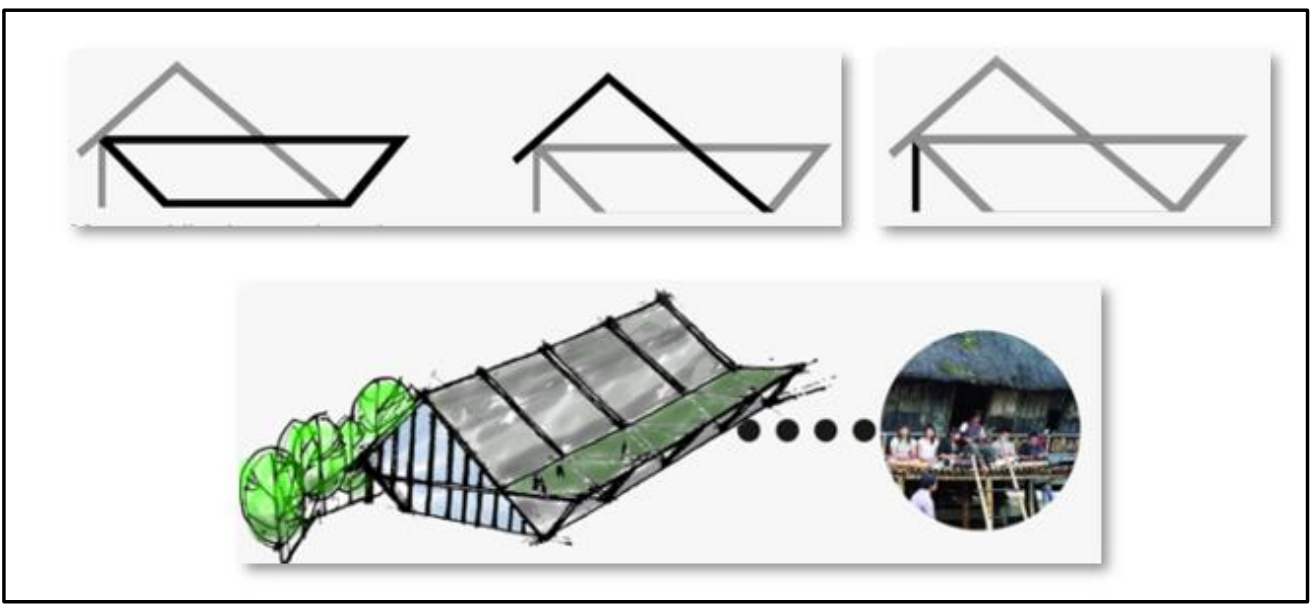

Figure 11. Workshop building concept 
Take the elements of the traditional house form Karo as wall roof and pillars. The primary way of all of the above use into the workshop building. And the results for pictures of the workshop building (Figure 12).

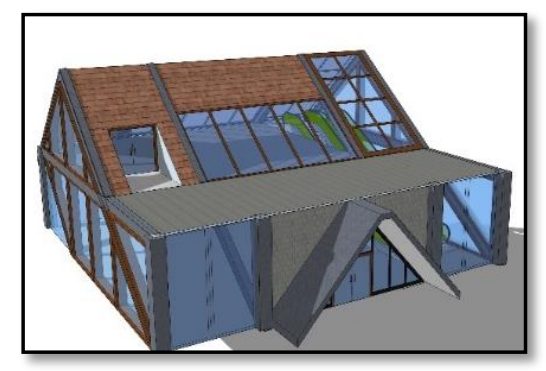

Figure 12. Workshop

For buildings workshop also adopted some form of creations-custom homes Karo and took his philosophy-philosophy to apply to ancillary buildings. Like using true or terraces in the area as a place to disable workshop. And others. Can be seen in (Figure 13).

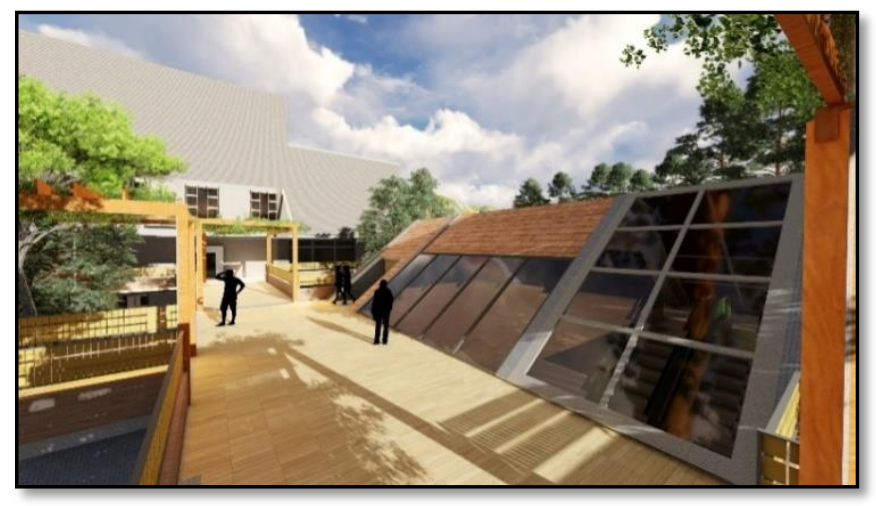

Figure 13. Workshop

For the final design looks at the picture of which 14 between the main building and workshops connected via the sky bridge (Figure 14).

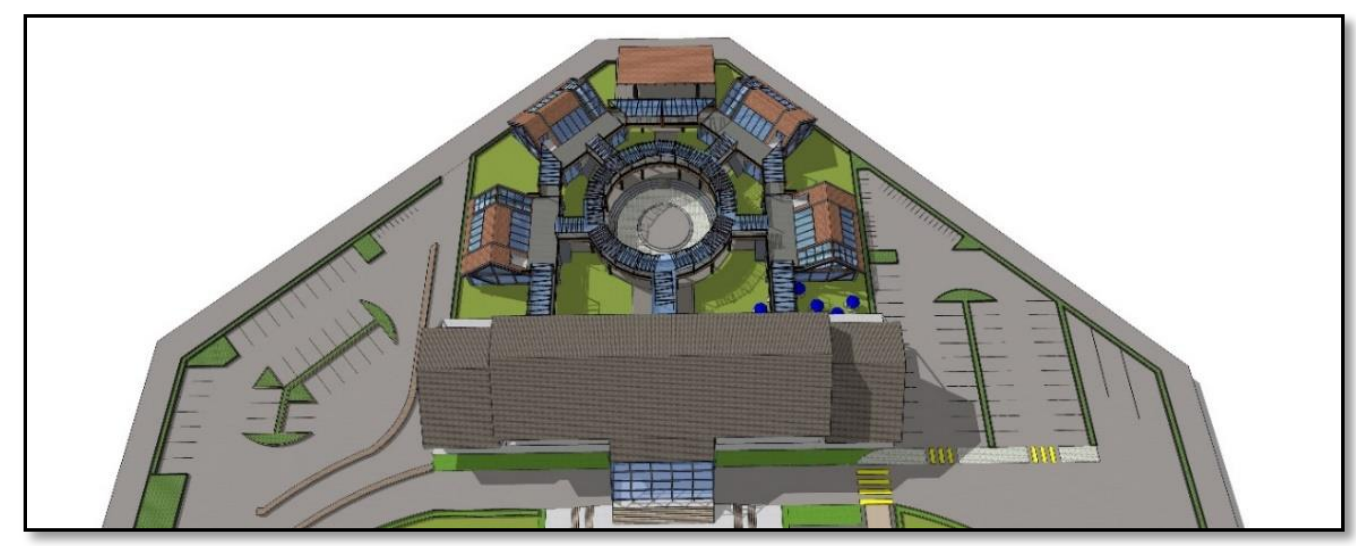

Figure 14. Site 


\section{Conclusion}

The cultural center is a container or place intended to introduce, studying, preserving culture Karo, addressed to the community, domestic and foreign tourists to better understand or know about the culture. There is in the land of Karo. Culture should be preserved and studied. Not only preserved but should be reviewed with the plunge of the practice to get the "typical experience" in each person who considers it. Without culture, there will be no human diversity and lifestyle. Application of vernacular neo theme at design seen from the Karo applied custom homes that include aspects of physical and nonphysical.

\section{Acknowledgment}

This research is dedicated to the community to educate insights into Karo culture. Also to local governments to increase tourists in Karo District.

\section{REFERENCES}

[1] M. Wehelmina, "Re-Design Taman Budaya Sulawesi Utara di Manado Neo- Vernacular Architecture," p. 35, 2015.

[2] M. P. Ir.M.Nawawiy loebis, RAIBNYA PARA DEWA KAJIAN ARSITEKTUR KARO, MEDAN: Bina Teknik Press, 2004.

[3] C. Jencks, Late-Modern Architecture and Other Essays, New York: Rizzoli, 1980. 